Erdelyi, G., 1962 "Gynaecological survey of female athletes". J.Sports Med. 2: 174-179.

Fanstil, D. D. and Park, C. S., 1981 "Steroid hormones and the kidney". Ann.Rev.Physiol. 43: 637-649.

Fox, E. L. and Mathews, D. K., 1981 "Cardiorespiratory considerations, Section $3^{\prime \prime}$. In The physiological basis of physical education and athletics. Saunders College pubs. 3rd edition, 183-251.

Pitkin, R. M., Reynolds, W. A., Williams, G. A. and Hargis, G. K., 1978 "Calcium regulating hormones during the menstrual cycle". J.Clin.Endocrin.Metab. 47: 626-632.

Pitts, R. F., 1972 "Physiology of the kidney and body fluids". Yr.bk.Med.Pubs. 3rd edition, 60-95.
Strott, C. A., Yoshimi, T., Ross, C. T. and Lipsett, M. B., 1969 "Ovarian physiology relationship between plasma $\mathrm{LH}$ and steroidogenesis by the follicle and corpus luteum; effect of HCG". J.Clin.Endocr. 29: 1157-1167.

Varley, H., Gowenlock, A. H. and Bell, M., 1976. Practical Clinical Biochemistry. Vol. 2, 5th edition, Heinemann, London.

Wootton, I-D. P., 1964 Micro-analysis in medical biochemistry. J. A. Churchill (Ed.).

Zaharieva, S., 1965 "Survey of sports women at the Tokyo Olympics". J.Sports Med.Phys. Fitness 5: 215-217.

Zambraski, E. J., Tipton, C. M., Jordan, H. R., Palmer, W. K. and Tcheng, T. K. 1974 "lowa wrestling study; urinary profiles of state finalists prior to competition". Med. \& Sci. in sports 6: 129-132.

Title:

BOOK REVIEW

Author:

\title{
RUNNING WITHOUT FEAR
}

Publisher:

Kenneth H. Cooper

Bantam Books

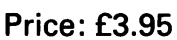

\author{
ISBN 055317356
}

This is the latest in a series of books on exercise written by Kenneth Cooper, the US doctor often credited with coining the term 'aerobics'. The title presupposes that people are afraid whilst running and requires explanation. The book was written to allay the anxiety raised in the minds of Americans when Jim Fixx, committed jogger and author of the best-selling book "The Complete Book of Running", died whilst out running. This event re-opened the debate about the relative risks and advantages of taking exercise and "Running without Fear" is Cooper's contribution to this debate. His preoccupation with the individual case of Jim Fixx is evident throughout the book. The first 70 pages (of 209) are devoted to the topic of sudden death during exercise but there are also chapters on understanding coronary risk factors, on suitable forms of aerobic exercise and on exercise stress tests (with much emphasis on the protocol used in the Cooper Clinic).

It is difficult to know for what audience the book is intended. The analysis of coronary risk factors is a useful and readily understood summary for the layman who may also appreciate the practical advice about topics such as warm up. He is unlikely, however, to have much interest in or understanding of details of abnormal ECG responses to a treadmill stress test and subsequent diagnosis and management (Chapter 8). On the other hand, the clinician would doubtless prefer to share Cooper's undoubted wealth of experience with exercise testing through the scientific literature. No reference is made to such publications in the list of selected recent papers on risks and benefits of exercise which follows the text. The book is a curious mixture of anecdotal, even evangelical, tales about the role of exercise in maintaining health and a serious attempt to describe and interpret the scientific evidence of this topic.

Adrianne E. Hardman

Title:

Author:

Publisher:

\section{ESSENTIALS OF SPORTS MEDICINE}

Greg R. McLatchie

Churchill Livingstone, Edinburgh

Price: $£ 14.95$

\section{BOOK REVIEW}

The name of Greg McLatchie is sufficient in itself to be a guarantee for this excellent introduction to Sports Medicine. The immediate appeal of this compilation is that it introduces subjects rarely found in other books on the subject. There are contributions on sport and the law, the role of exercise in prevention and treatment of disease and a code of ethics for doctors involved in treating sports players. These are all subjects of considerable concern, particularly when there is increasing public interest in the medical problems of the famous and increasing public participation in sport. In a book of only 200 pages or so, covering the whole range of Sports Medicine from diet to sudden death, from training to treatment, it is not surprising that subjects are not covered in depth. It is a book on the essentials of Sports Medicine and the essentials it deals with very well. I particularly liked the section on physiotherapy and strapping, subjects that most of us know little about.

One or two minor niggles. Chondromalacia patella has largely been abandoned as a diagnosis and I would venture to suggest that the physical signs described for anterior knee pain are not all that common. Incidentally, the main description of the condition is not indexed. As may be expected, there is an emphasis on injuries in combat and contact sports, perhaps at the expense of the more popular running and racquet sports. Stress fractures, which are an increasingly common problem, receive little coverage and again the indexing, ss suspect, one reference being to another page of the index. However, all in all, a good book for all GPs prepared to take an interest in their patients' sporting life and certainly useful reading for those embarking on the BASM courses. Available, on loan, from the BASM library. 